\title{
Highly Enhanced Vapor Sensing of Multiwalled Carbon Nanotube Network Sensors by $\boldsymbol{n}$-Butylamine Functionalization
}

\author{
P. Slobodian, ${ }^{1,2}$ P. Riha, ${ }^{3}$ P. Cavallo, ${ }^{4}$ C. A. Barbero, ${ }^{4}$ R. Benlikaya, ${ }^{2,5}$ U. Cvelbar, ${ }^{6}$ \\ D. Petras, ${ }^{1}$ and P. Saha ${ }^{1,2}$ \\ ${ }^{1}$ Polymer Centre, Faculty of Technology, Tomas Bata University in Zlin, 76001 Zlin, Czech Republic \\ ${ }^{2}$ Centre of Polymer Systems, University Institute, Tomas Bata University, Nad Ovcirnou 3685, 76001 Zlin, Czech Republic \\ ${ }^{3}$ Institute of Hydrodynamics, Academy of Sciences, 16612 Prague, Czech Republic \\ ${ }^{4}$ Departamento de Química, Universidad Nacional de Rio Cuarto, 5800 Rio Cuarto, Argentina \\ ${ }^{5}$ Department of Secondary Science and Mathematics Education, Faculty of Necatibey Education, Balikesir University, \\ 10100 Balikesir, Turkey \\ ${ }^{6}$ Jozef Stefan Institute F4, Jamova Cesta 39, 1000 Ljubljana, Slovenia
}

Correspondence should be addressed to P. Slobodian; slobodian@ft.utb.cz

Received 24 April 2014; Revised 26 June 2014; Accepted 1 July 2014; Published 21 August 2014

Academic Editor: Keita Kobayashi

Copyright (C) 2014 P. Slobodian et al. This is an open access article distributed under the Creative Commons Attribution License, which permits unrestricted use, distribution, and reproduction in any medium, provided the original work is properly cited.

\begin{abstract}
The sensing of volatile organic compounds by multiwall carbon nanotube networks of randomly entangled pristine nanotubes or the nanotubes functionalized by $n$-butylamine, which were deposited on polyurethane supporting electrospinned nonwoven membrane, has been investigated. The results show that the sensing of volatile organic compounds by functionalized nanotubes considerably increases with respect to pristine nanotubes. The increase is highly dependent on used vapor polarity. For the case of highly polar methanol, the functionalized MWCNT network exhibits even more than eightfold higher sensitivity in comparison to the network prepared from pristine nanotubes.
\end{abstract}

\section{Introduction}

Carbon nanotube (CNT) networks many times referred to as buckypapers are able to detect various gases or even different organic vapors [1-3]. The mechanism of detection involves adsorption of analyte molecules on CNT surface by van der Waals forces. The strength of forces and the interaction area between CNTs and gas molecules raise the adsorption and increase the amount of adsorbed molecules. All this leads to the change of electron density on CNTs, the increase of contact resistance between touching nanotubes, and, consequently, the electrical resistance change of whole CNT networks [3].

The vapor sensing properties of CNT networks can be improved by a nanotube surface alteration to affect affinity of vapor molecules. Mostly, oxidation $[1,4]$, plasma treatment $[5,6]$, or chemical functionalization $[3,7,8]$ is used. The modified CNT networks with different selectivity to particular vapors or group of vapors may be assembled into multiple sensory heads sometimes called electronic nose. Comparison of the sensory head data with a library of responses may specify a monitored vapor.

The aim of this study is to examine sensing properties of $n$-butylamine functionalized multiwall carbon nanotube (MWCNT) networks attached to a supporting polyurethane nonwoven filter to solvent vapors of different polarities defined by total Hildebrand solubility parameter.

\section{Experimental}

2.1. Materials and Procedures. The purified MWCNTs of acetylene type were supplied by Sun Nanotech Co. Ltd., China (diameter $10-30 \mathrm{~nm}$, length $1-10 \mu \mathrm{m}$, purity $>90 \%$, and volume resistance $0.12 \Omega \mathrm{cm}$ according to supplier). The complete information about the used pristine MWCNT can be found in our previous work [9], where the results of TEM analysis are presented. The diameter of individual 
nanotubes was determined within the range 10 and $60 \mathrm{~nm}$ (100 measurements), the average diameter and standard deviation $15 \pm 6 \mathrm{~nm}$, and the length from tenths of micron up to $3 \mu \mathrm{m}$. The nanotube wall consists of about 15 to 35 rolled layers of graphene. $n$-Butylamine $\left(\mathrm{BuNH}_{2}\right)$, thionyl chloride $\left(\mathrm{SOCl}_{2}\right)$, and dimethylformamide (DMF) were supplied by Sigma Aldrich and triethylamine by Merck. The functionalization which yields oxidized groups covalently attached onto nanotube surface was performed in mixture of $\mathrm{H}_{2} \mathrm{SO}_{4}+\mathrm{HNO}_{3}$ under reflux for 0.5 hours. These groups are binding elements for the amine functional groups. $\mathrm{BuNH}_{2}$ functionalized nanotubes were prepared in a $250 \mathrm{~mL}$ roundbottomed flask filled with $0.3 \mathrm{~g}$ of $\mathrm{MWNT}$ treated by $\mathrm{HNO}_{3}+$ $\mathrm{H}_{2} \mathrm{SO}_{4}$ and $30 \mathrm{~mL}$ of $\mathrm{SOCl}_{2}$. The mixture was stirred at $80^{\circ} \mathrm{C}$ for $24 \mathrm{~h}$ and then decanted and the rest of unreacted $\mathrm{SOCl}_{2}$ was removed under vacuum. Afterwards, $10 \mathrm{~g}$ of $\mathrm{BuNH}_{2}$ in $15 \mathrm{~mL}$ of DMF was added to the mixture and dispersed by sonication in a water bath at $35^{\circ} \mathrm{C}$ for $30 \mathrm{~min}$. Finally, the reaction proceeded at $65-75^{\circ} \mathrm{C}$ for $24 \mathrm{~h}$ in the presence of triethylamine as a catalyst. The nanotubes were then rinsed by acetone and ethanol to remove any remains of modifiers before network preparation. The amine treated MWCNTs are further on denoted as MWCNT $\left(\mathrm{BuNH}_{2}\right)$ and the pristine ones as MWCNT (pure).

The nanotubes were used for the preparation of aqueous paste: $1.6 \mathrm{~g}$ of MWCNTs and $\sim 50 \mathrm{~mL}$ of deionized water were mixed with the help of a mortar and pestle. The paste was then diluted in deionized water with sodium dodecyl sulfate (SDS) and 1-pentanol. Consequently, $\mathrm{NaOH}$ aqueous solution was added to adjust $\mathrm{pH}$ to the value of 10 . The final nanotube concentration in the suspension was $0.3 \mathrm{wt}$. \%, and the concentration of SDS and 1-pentanol was $0.1 \mathrm{M}$ and $0.14 \mathrm{M}$, respectively. The dispersion was homogenized using UZ Sonopuls HD 2070 kit for $30 \mathrm{~min}$ at $50 \%$ power of the apparatus and in $50 \%$ pulse mode under the temperature of about $50^{\circ} \mathrm{C}$ [1]. The homogenized dispersion of nanotubes was vacuum filtered through the nonwoven polyurethane (PU) membrane. The disk-shaped filtration cake was washed several times by deionized water and methanol in situ. The cake forms an entangled nanotube network which is partially infiltrated into the membrane pores. This interlocked structure of MWCNT network and PU membrane is used as a sensor in sensing experiments.

Polyurethane nonwoven porous membrane for MWCNT dispersion filtration was prepared by electrospinning. PU solution in dimethylformamide (DMF) based on $4,4^{\prime}$ methylene-bis(phenyl isocyanate) (MDI), poly(3methyl-1,5pentanediol)-alt-(adipic, isophthalic acid) (PAIM), and 1,4butanediol (BD) was synthesized in molar ratio 9:1:8 (PU 918) at $90^{\circ} \mathrm{C}$ for 6 hours. Per partes method of synthesis was used starting with preparation of prepolymer from MDI and PAIM and followed by addition of BD and remaining quantity of MDI. The prepared solution was diluted with $\mathrm{DMF}$ to reduce the viscosity to 1.3 Pas (PU concentration of 13 wt. \%) and to increase the conductivity to $150 \mu \mathrm{S} / \mathrm{cm}$. Nanofibre layers were prepared from PU solution by the commercially available equipment SpinLine 120 (SPUR a.s., Zlin, Czech Republic, http://www.spur-nanotechnologies.cz) using nanofibre forming jets. The experimental conditions were as follows: relative humidity of $34 \%$, temperature of $23^{\circ} \mathrm{C}$, electric voltage applied to PU solution of $95 \mathrm{kV}$, distance between electrodes of $270 \mathrm{~mm}$, and speed of supporting textile collecting nanofibres of $0.2 \mathrm{~m} / \mathrm{min}$. Nanofibre layer with area mass of about $2.5 \mathrm{~g} / \mathrm{m}^{2}$ and average pore size distribution of about $500 \mathrm{~nm}$ was collected on the polypropylene nonwoven textile.

\subsection{Characterization of Nanotube Networks. MWCNTs} (pure) were analyzed via transmission electron microscopy (TEM) using microscope JEOL JEM 2010 at the accelerating voltage of $160 \mathrm{kV}$. The sample was deposited on 300 mesh copper grid with a carbon film (SPI, USA) from MWCNT dispersion in acetone prepared by ultrasonication and dried.

The structure of PU filtering membrane and MWCNT networks were observed with the help of scanning electron microscope (SEM) Vega LMU, produced by Tescan Ltd. The samples were deposited on carbon targets and covered with a thin $\mathrm{Au} / \mathrm{Pd}$ layer. For the observations, the regime of secondary electrons was chosen.

The networks were also analyzed by X-ray photoelectron spectroscopy (XPS) on TFA XPS Physical Electronics instrument at the base pressure in the chamber of about $6 \times 10^{-8} \mathrm{~Pa}$. The samples were excited with X-rays over a $400 \mu \mathrm{m}$ spot area with a monochromatic $\mathrm{Al} K_{\alpha 1,2}$ radiation at $1486.6 \mathrm{eV}$. Photoelectrons were detected with a hemispherical analyzer positioned at an angle of $45^{\circ}$ with respect to the normal to the sample surface. Survey-scan spectra were made at the pass energy of $187.85 \mathrm{eV}$, and the energy step was $0.4 \mathrm{eV}$. Individual high-resolution spectra for $\mathrm{Cl}$ s were taken at a pass energy of $23.5 \mathrm{eV}$ and $0.1 \mathrm{eV}$ energy step. The concentration of elements was determined from survey spectra by MultiPak v7.3.1 software from Physical Electronics.

Fourier transform infrared (FTIR) analyses of MWCNT samples in powder form prepared by $\mathrm{KBr}$ were performed using Thermo Scientific Nicolet IS5 spectrometer with ID1 transmission accessory.

2.3. Electrical Resistance Measurement. The electrical resistance of sensors (length $15 \mathrm{~mm}$, width $5 \mathrm{~mm}$, and thickness ca $0.3 \mathrm{~mm}$ ) cut out from the prepared MWCNT network/PU membrane discs was measured along the sensor length by the two-point technique using multimeter Sefram 7338. The sensor was placed on a planar holder with $\mathrm{Cu}$ electrodes fixed on both of its sides. The holder with the sensor was placed into the gas chamber set on temperature $40^{\circ} \mathrm{C}$; see schematic illustration in Figure 1. The air as a gas carrier is pumped (flow rate $1.6 \mathrm{~mL} / \mathrm{s}$ ) through the silica gel into evaporation chamber, with temperature set to $100^{\circ} \mathrm{C}$. The analyte $(150 \mu \mathrm{L})$ was injected into evaporation chamber where it evaporated and its effect on the sensor resistance in gas sensing chamber was measured. The measurement was performed in three repeated 6-minute injection cycles. Experimental VOC used for testing performance of the sensor covered broad range of polarities from nonpolar solvents like hydrocarbons to polar alcohols. 


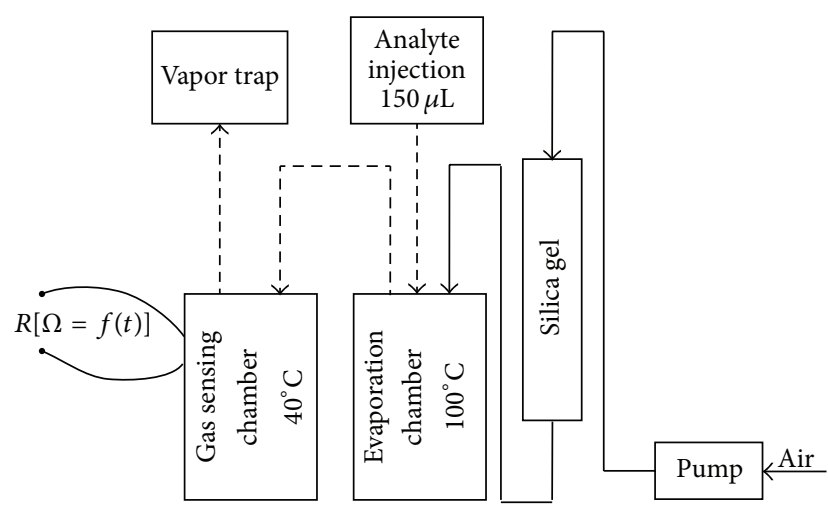

FIGURE 1: Schematic illustration of experimental setup for gas resistive sensors based on CNT/PUR segregated composite to concentration pulse of VOC vapors.

$$
\mathrm{CNT} \stackrel{\mathrm{H}_{2} \mathrm{SO}_{4}+\mathrm{HNO}_{3}}{\longrightarrow} \mathrm{CNT}-\mathrm{COOH} \stackrel{\mathrm{SOCl}_{2}}{\longrightarrow}
$$$$
\mathrm{CNT}-\mathrm{COCl} \stackrel{\mathrm{NH}_{2}-\mathrm{CH}_{2}-\mathrm{CH}_{2}-\mathrm{CH}_{2}-\mathrm{CH}_{3}}{\longrightarrow} \text { CNT-CONH- }\left(\mathrm{CH}_{2}\right)_{3}-\mathrm{CH}_{3}
$$

Figure 2: Possible reaction route for MWCNT functionalization by $\mathrm{BuNH}_{2}$.

\section{Results}

Oxidation of MWCNTs by $\mathrm{HNO}_{3}+\mathrm{H}_{2} \mathrm{SO}_{4}$ leads to formation of carboxyl, quinone, and hydroxyl groups on the surface of nanotubes with the following result: the concentration of carboxyl group is higher than other groups [10]. The possible mechanism of MWCNT oxidation by $\mathrm{HNO}_{3}+\mathrm{H}_{2} \mathrm{SO}_{4}$ and subsequent functionalization by $\mathrm{BuNH}_{2}$ is illustrated in Figure 2. The first step of oxidation by $\mathrm{HNO}_{3}+\mathrm{H}_{2} \mathrm{SO}_{4}$ mixture increases the content of carboxylic groups covalently bonded to nanotube surface. Then the carboxylic groups are converted to acyl chloride groups using $\mathrm{SOCl}_{2}$. Finally, butyl amine molecules are bonded to MWCNTs to produce amide groups $(-\mathrm{CONH})$. FTIR and XPS measurements were used to observe the changes in the structure of pristine MWCNTs after the amidation. FTIR spectra of $\mathrm{BuNH}_{2}$, pure MWCNT, and MWCNT $\left(\mathrm{BuNH}_{2}\right)$ are given in Figure 3. The peaks of $\mathrm{BuNH}_{2}$ at 1602 and $1463 \mathrm{~cm}^{-1}$ can be attributed to $-\mathrm{NH}_{2}$ and $-\mathrm{CH}_{2} / \mathrm{CH}_{3}$ groups. In the FTIR spectrum of pure MWCNTs, the peaks at 1731, 1580 , and $1460 \mathrm{~cm}^{-1}$ can belong to ester group, $\mathrm{C}=\mathrm{C}$ stretching mode, and $-\mathrm{CH}_{2} / \mathrm{CH}_{3}$ groups, respectively [11]. The peak assigned to quinone group at $1646 \mathrm{~cm}^{-1}$ [12] in FTIR spectrum of pure MWCNTs shifts to $1642 \mathrm{~cm}^{-1}$ after the amidation. The disappearance of the peak at $1731 \mathrm{~cm}^{-1}$ and the appearance of the peak at $1710 \mathrm{~cm}^{-1}$ show the hydrolysis of the ester groups to carboxylic acid in the acid mixture and the presence of unreacted carboxyl groups in the structure of MWCNT $\left(\mathrm{BuNH}_{2}\right)$, respectively. The peaks about $1460 \mathrm{~cm}^{-1}$ show $-\mathrm{CH}_{2} / \mathrm{CH}_{3}$ groups on both MWCNTs.

Surface composition (at \%) of pristine MWCNTs changes after treatment from $85.8 \%(\mathrm{C})$ and $14.2 \%(\mathrm{O})$ to $87.5 \%$
(C), $8.9 \%(\mathrm{O})$, and $3.5 \%(\mathrm{~N})$ for MWCNT $\left(\mathrm{BuNH}_{2}\right)$. Figure 4(a) shows the typical peaks of XPS survey spectra for C1s positioned at $284.78 \mathrm{eV}$, O1s at $527.7 \mathrm{eV}$, and N1s at $399.2 \mathrm{eV}$. The N1s peak at $399.2 \mathrm{eV}$ originating on MWCNT $\left(\mathrm{BuNH}_{2}\right)$ confirms the presence of amide functional groups on the MWCNT $\left(\mathrm{BuNH}_{2}\right)$ samples [12]. Figure 4(b) shows a broaden peak at $284.79 \mathrm{eV}$ with $60.2 \%$ of the total C$\mathrm{C}$ bond $\left(1 \mathrm{~s}, \mathrm{sp}^{2}\right)$ area on the surface of pristine MWCNTs. Other peaks at $285.78 \mathrm{eV}(18.8 \%), 287.06 \mathrm{eV}(15.5 \%)$, $289.41 \mathrm{eV}(2.6 \%)$, and $290.46 \mathrm{eV}(2.8 \%)$ can be attributed to $\mathrm{sp}^{3}$ hybridized $\mathrm{C}-\mathrm{C}$ bonds present at defective locations and tubular structure asymmetry $[13,14], \mathrm{C}-\mathrm{O}, \mathrm{C}=\mathrm{O}$, and $\mathrm{O}-\mathrm{C}=\mathrm{O}$ groups, and $\pi-\pi$ electronic transition in pristine MWCNTs, respectively. The shifting of the peak from 287.06 to $286.99 \mathrm{eV}$ as seen in Figure 4(c) could be reason for the formation of amide groups in the structure of $\mathrm{MWCNT}\left(\mathrm{BuNH}_{2}\right)$. The increase in the area \% of $\mathrm{sp}^{3}$ hybridized $\mathrm{C}-\mathrm{C}$ bonds could arise from the additional alkyl groups of $\mathrm{BuNH}_{2}$. The reason of the fact that the peak of $\mathrm{O}-\mathrm{C}=\mathrm{O}$ group shifts from 289.41 to $288.41 \mathrm{eV}$ [15] can be the hydrolysis of the ester groups on pure MWCNTs to the carboxylic groups on MWCNT $\left(\mathrm{BuNH}_{2}\right)$, which is confirmed by their FTIR spectra. However, the presence of the peak at $288.41 \mathrm{eV}$ after modification shows that there are still unreacted carboxyl groups with $\mathrm{BuNH}_{2}$ on its surface. It is clear that the findings of XPS and FTIR measurements compromise with each other and confirm expected modification. It was seen in the previous study [3] that the peaks of $-\mathrm{NH}_{2}$ and $\mathrm{C}=\mathrm{C}$ vibrations were coupled with each other in the case of the alkyl diamine treated MWCNTs. In our case, the increase in the intensity of the peak at $1580 \mathrm{~cm}^{-1}$ could arise from the residue of unreacted $n$-butylamine in the structure of the MWCNTs because of the observation of two different peaks in the deconvoluted N1s spectra; see Figure 4(d). In another study, the atoms of nitrogen with a bonding energy of $400.0 \mathrm{eV}$ and $401.0 \mathrm{eV}$ were assigned to the bonds involving primary amines $\left(-\mathrm{CH}_{2}-\right.$ $\mathrm{NH}_{2}$ ) and amide carbonyl groups $(-\mathrm{N}-\mathrm{C}=\mathrm{O})$, respectively [14], which supports the presence of the amine and amide groups on MWCNT $\left(\mathrm{BuNH}_{2}\right)$. XPS and FTIR data show us that there are also physically adsorbed n-butyl amine molecules on MWCNTs as well as chemically reacted ones.

Figure 5 shows results of TEM analyses of pristine MWCNTs. The micrograph of the cluster of nanotubes is shown in Figure 5(a) and detailed view of one individual nanotube is in Figure 5(b). The partial infiltration of MWCNTs into the membrane pores links MWCNT entangled layer with PU membrane.

SEM micrographs of the upper surfaces of prepared two principal nanotube networks are presented in Figures 6(A) and 6(B). The micrographs show some differences in the porosity of the networks. $\mathrm{BuNH}_{2}$ treated nanotubes seem to form a network with higher porosity than pristine nanotubes. At the same time the functionalization of CNT network by $\mathrm{BuNH}_{2}$ may cause the increase in the surface area of MWCNT $\left(\mathrm{BuNH}_{2}\right)$ network [3]. So the believed increase in porosity and the surface area of MWCNT $\left(\mathrm{BuNH}_{2}\right)$ network may be behind the improvement of adsorption properties of this network [16]. Figure 6(C) presents SEM analyses of 


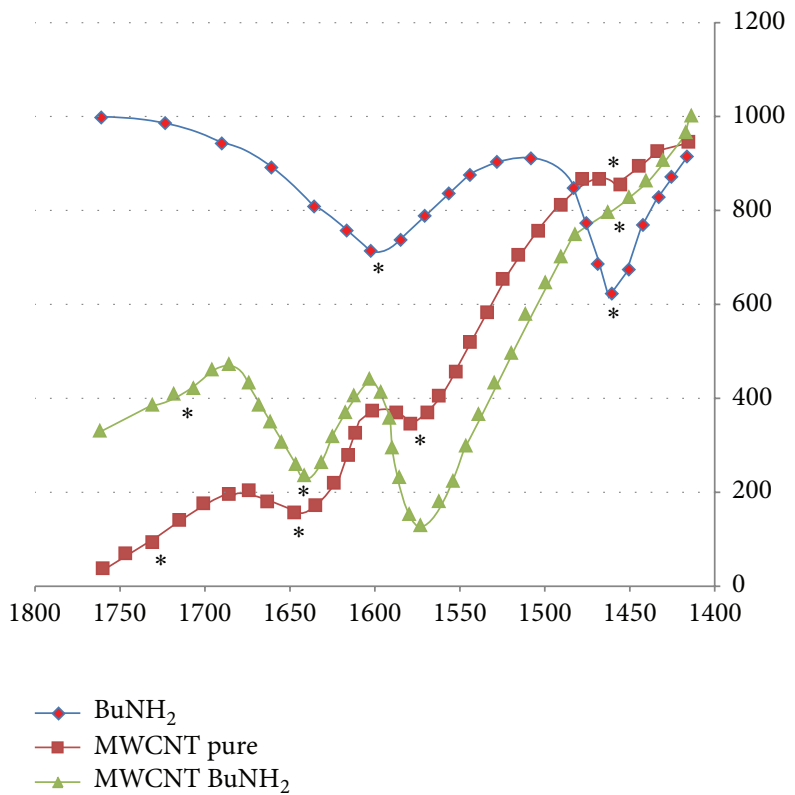

Figure 3: FTIR spectra of $\mathrm{BuNH}_{2}$, pure MWCNTs, and MWCNT $\left(\mathrm{BuNH}_{2}\right)$.

TABLE 1: Sensor responses $S_{1}$ and $S_{2}$ of sensors with pristine and functionalized MWCNT, respectively, to concentration pulses of different VOC in air from a broad range of polarities defined by Hansen solubility parameters $\delta_{d}, \delta_{p}$, and $\delta_{h}$ and total Hildebrand solubility parameter, $\delta_{t}$.

\begin{tabular}{|c|c|c|c|c|c|c|c|}
\hline Solvent & $\begin{array}{c}\delta_{d} \\
{\left[\mathrm{MPa}^{1 / 2}\right]}\end{array}$ & $\begin{array}{c}\delta_{p} \\
{\left[\mathrm{MPa}^{1 / 2}\right]}\end{array}$ & $\begin{array}{c}\delta_{h} \\
{\left[\mathrm{MPa}^{1 / 2}\right]}\end{array}$ & $\begin{array}{c}\delta_{t} \\
{\left[\mathrm{MPa}^{1 / 2}\right]}\end{array}$ & $\begin{array}{l}S_{1} \\
{[\%]}\end{array}$ & $\begin{array}{c}S_{2} \\
{[\%]}\end{array}$ & $\begin{array}{c}\left(S_{2} / S_{1}-1\right) \times 100 \\
{[\%]}\end{array}$ \\
\hline n-Pentane & 14.5 & 0 & 0 & 14.5 & 8.0 & 10 & 25.0 \\
\hline n-Heptane & 15.3 & 0 & 0 & 15.3 & 6.5 & 8.0 & 23.1 \\
\hline $\begin{array}{l}\text { Diisopropyl } \\
\text { ether }\end{array}$ & 13.8 & 2.8 & 4.6 & 14.8 & 8.4 & 12.3 & 46.4 \\
\hline Diethyl ether & 15.5 & 2.9 & 4.6 & 16.4 & 8.5 & 17.0 & 100.0 \\
\hline Ethyl acetate & 15.8 & 5.3 & 7.2 & 18.2 & 9.3 & 22.0 & 136.6 \\
\hline 2-Butanone & 16.0 & 9.0 & 5.1 & 19.1 & 8.2 & 26.3 & 220.7 \\
\hline Chloroform & 15.3 & 18.0 & 6.1 & 24.4 & 4.6 & 20.5 & 345.7 \\
\hline 1-Pentanol & 16.0 & 6.8 & 17.4 & 24.6 & 5.0 & 28.0 & 460.0 \\
\hline Methanol & 15.1 & 12.3 & 22.3 & 29.6 & 3.8 & 35.8 & 842.1 \\
\hline
\end{tabular}

the used PU filtering membrane prepared by electrospinning as described above. The membrane has a porous structure. The pore size is in the range $50-500 \mu \mathrm{m}$; the PU fiber diameter is about $120 \mathrm{~nm}$. In the course of filtration, the membrane pores were filled at first by nanotubes and then a filtration cake forms.

The adsorption of solvent molecules by the network increases its electrical resistance and thus the network resistance measurement is a simple and convenient method to register MWCNT response to vapor action. The network sensor response $S$ may be defined as

$$
S=100 \frac{\left(R-R_{0}\right)}{R_{0}}=100 \frac{\Delta R}{R_{0}},
$$

where $R_{0}$ denotes the initial sensor resistance when, in the gas sensing chamber, it is exposed only to flow of pure air and
$R$ denotes the sensor resistance during measurement when exposed to a mixture of volatile organic compounds (VOC) with air. To compare the sensitivity of both tested composites, that is, MWCNT(pure) and $\operatorname{MWCNT}\left(\mathrm{BuNH}_{2}\right)$ networks on PU membrane to VOC vapors, the sensor response ratio was calculated: $\left(S_{2}-S_{1}\right) / S_{1}$; see Table $1 . S_{1}$ denotes the sensor response of MWCNT(pure)/PU composite and $S_{2}$ the sensor response of $\mathrm{MWCNT}\left(\mathrm{BuNH}_{2}\right) / \mathrm{PU}$ network.

The sensor response to VOC vapors was tested during adsorption/desorption cycles induced by VOC injection to flow of air. The chosen solvents cover a broad range of Hansen solubility parameters, as shown in Table 1 . The parameters are defined by

$$
\delta_{t}^{2}=\delta_{d}^{2}+\delta_{p}^{2}+\delta_{h}^{2}
$$




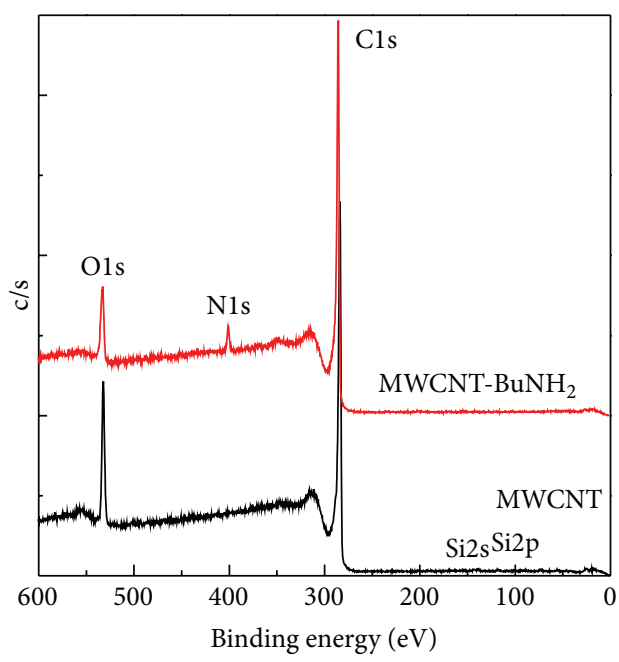

(a)

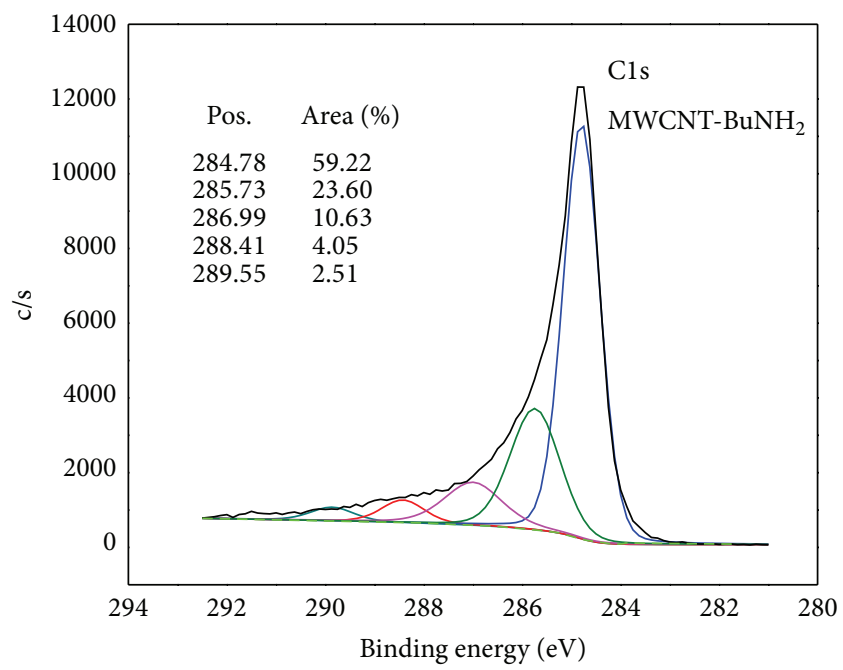

(c)

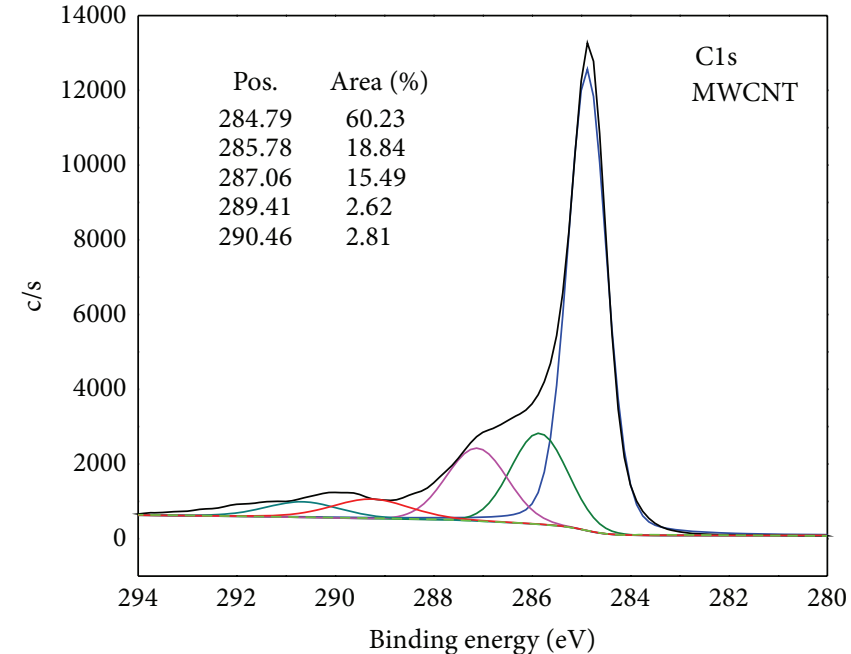

(b)

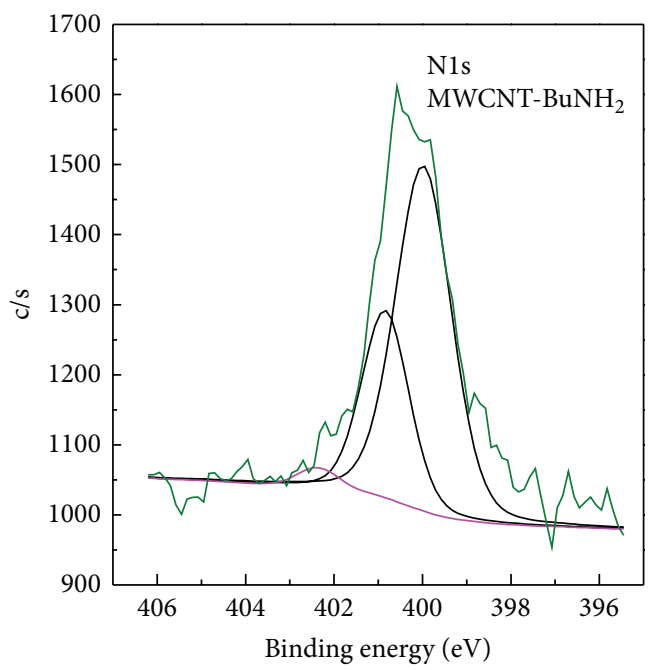

(d)

FIgURE 4: (a) XPS survey spectra of pure and $\mathrm{BuNH}_{2}$ treated MWCNTs. (b) Deconvoluted high resolution XPS peak C1s with functional groups for pure MWCNTs. (c) Deconvoluted high resolution XPS peak Cls with functional groups for $\mathrm{MWCNT}\left(\mathrm{BuNH}_{2}\right)$. (d) High resolution XPS spectra obtained in the N1s bonding energy region for MWCNT $\left(\mathrm{BuNH}_{2}\right)$.

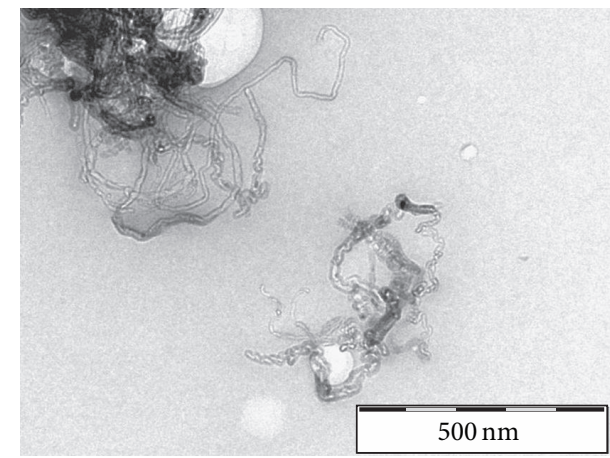

(a)

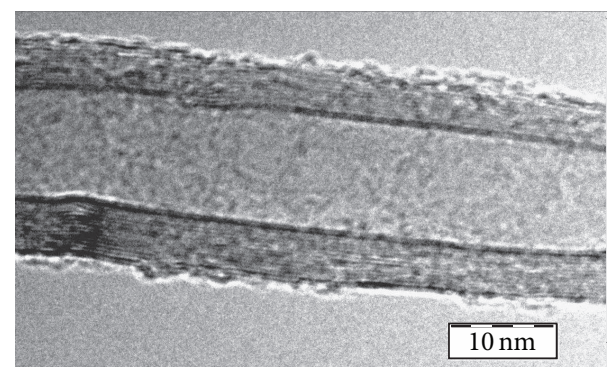

(b)

Figure 5: TEM micrographs of the pristine nanotubes. 

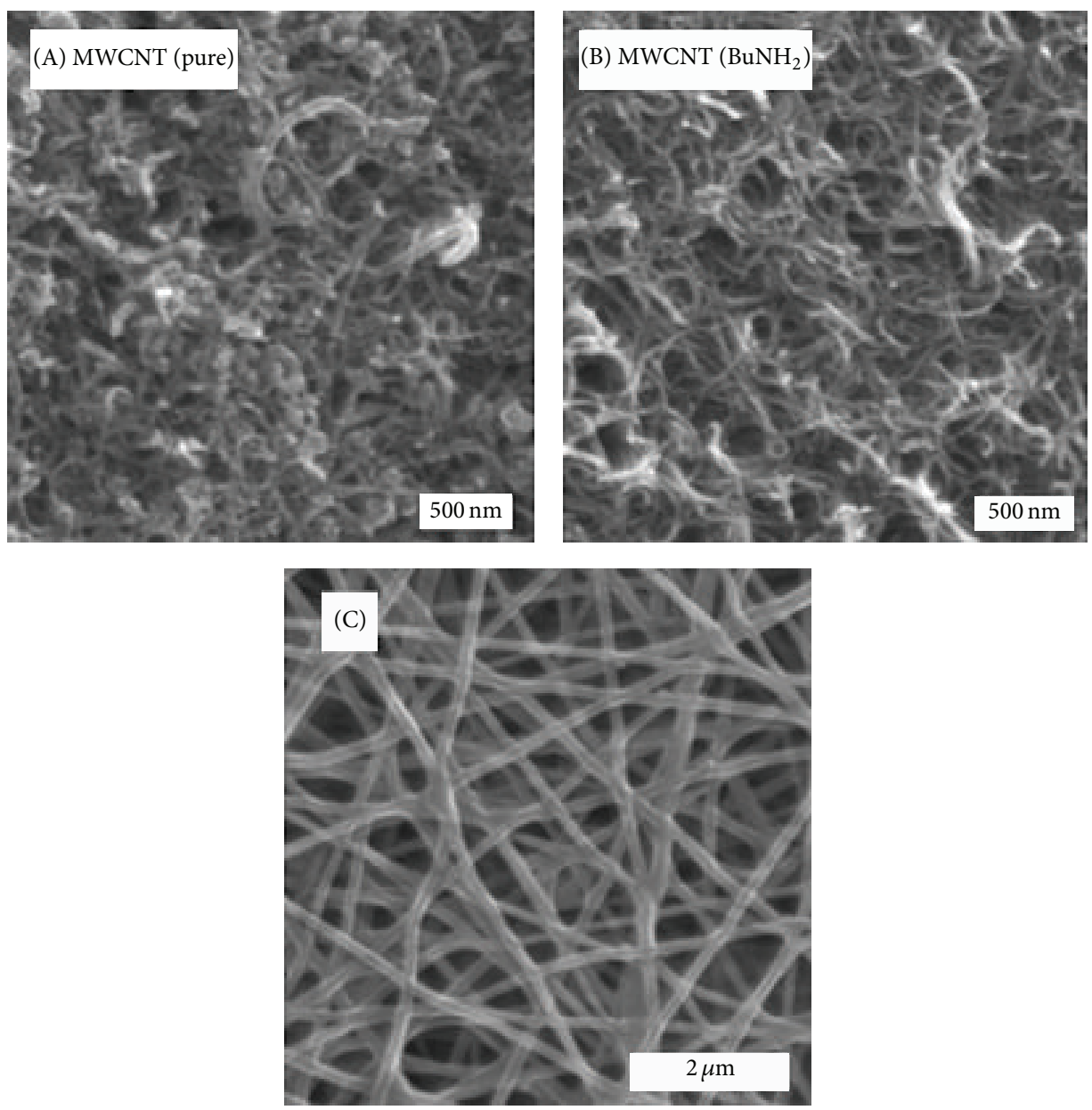

FIgURE 6: SEM micrographs of the surfaces of (A) pristine MWCNT and (B) MWCNT $\left(\mathrm{BuNH}_{2}\right)$ networks and (C) PU membrane.

where $\delta_{t}$ is the total Hildebrand solubility parameter and $\delta_{d}$, $\delta_{p}$, and $\delta_{h}$ denote dispersion, polar, and hydrogen bonding component, respectively.

The typical MWCNT network responses to VOC concentration pulses are presented in Figure 7. There are sharp increases in sensitivity value caused by adsorption of VOC molecules on CNT surface. Adsorbed molecules change contact resistance in CNT junction leading further to increase in macroscopic CNT layer resistance. Desorption of molecules leads to reversible decrease in macroscopic resistance. It seems that adsorption is faster than desorption process.

The interaction forces between MWCNT $\left(\mathrm{BuNH}_{2}\right)$ network and the VOC molecules are induced dipole-induced dipole, induced dipole-dipole, dipole-dipole, and hydrogen bonding as well as the interactions of coronene subunits on pure nanotubes. First and second group interactions are between alkyl groups $\left(-\mathrm{CH}_{2} / \mathrm{CH}_{3}\right)$ of VOC molecules and $-\mathrm{C}_{4} \mathrm{H}_{9}$ groups on MWCNT $\left(\mathrm{BuNH}_{2}\right)$ network and between the pair of alkyl groups $\left(-\mathrm{CH}_{2} / \mathrm{CH}_{3}\right)$ of VOC molecules and the polar groups (carboxyl and amide) on the network or the pair of polar groups of VOC molecules and the alkyl groups on the network, respectively. These interactions can provide the adsorption of $\mathrm{n}$-heptane and $\mathrm{n}$-pentane on MWCNT $\left(\mathrm{BuNH}_{2}\right)$ network, which are the weakest interactions between the network and VOCs in this study. The interactions of carboxyl and amide groups on MWCNT $\left(\mathrm{BuNH}_{2}\right)$ with polar groups of VOC molecules are involved in third and fourth group interactions based on the functional groups of VOC. The hydrogen bonding can have more important role for adsorption of methanol, n-pentanol, and chloroform on MWCNT $\left(\mathrm{BuNH}_{2}\right)$ network, which is the strongest interaction among them. The network has top three sensor responses to them. The reason of high sensor response of the network to methanol could be that methanol has the highest value of the sum of $\delta_{h}$ and $\delta_{d}$ among the VOCs. First, second, and third group interactions include the interactions of other VOCs with the network. Which interactions are more dominant on the adsorption changes with the solubility parameter values of VOCs as shown in Table 1. Second and third group interactions become prominent by the increase in the sum of $\delta_{h}$ and $\delta_{d}$ of VOCs. This usually causes the increase of sensor response of MWCNT $\left(\mathrm{BuNH}_{2}\right)$ network as seen in Figure 8.

\section{Conclusions}

Multiwalled carbon nanotubes (MWCNT) were used in their pure and functionalized form by $n$-butylamine to 

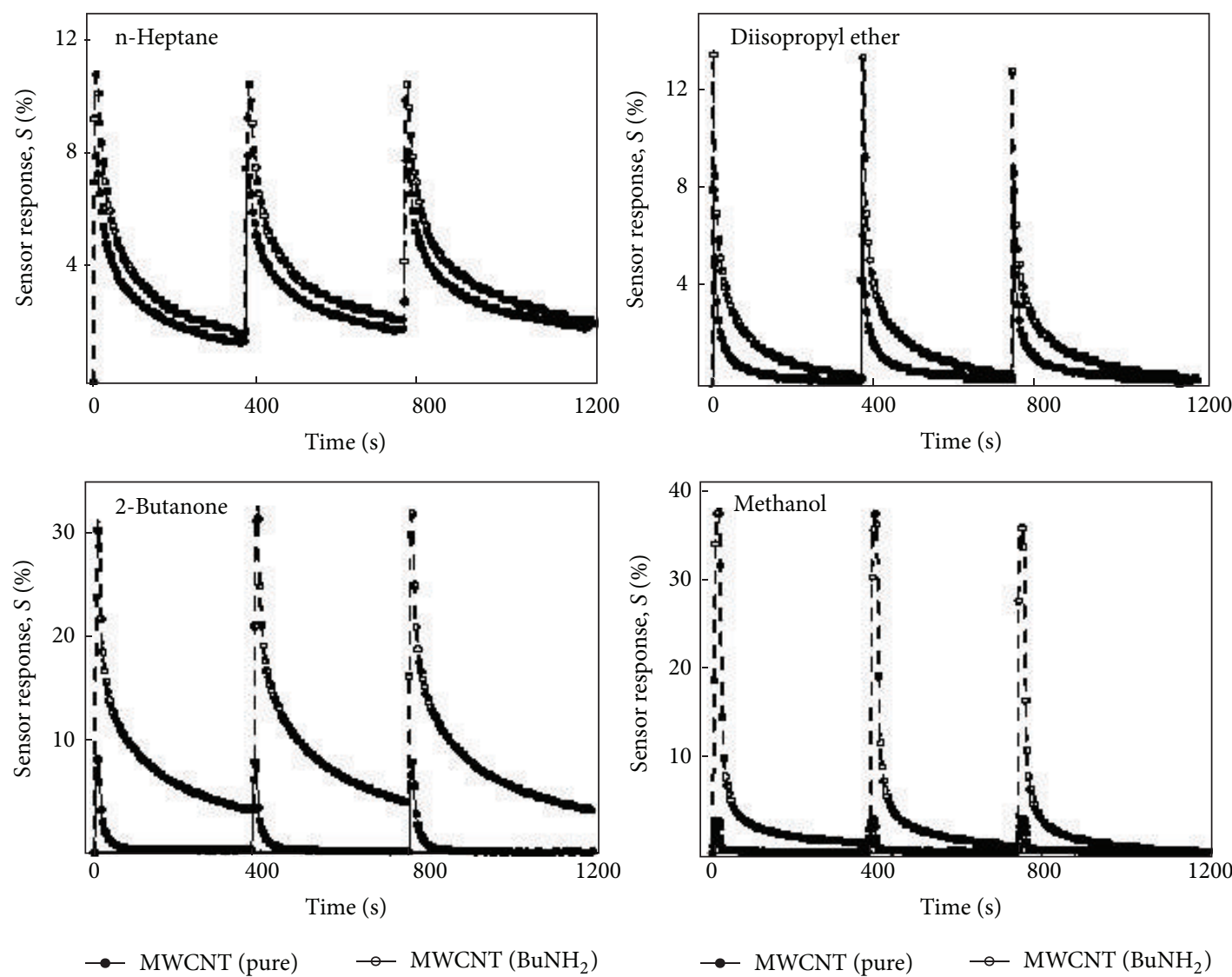

FIGURE 7: MWCNT/PU composite responses onto three concentration pulses of VOC vapours like heptane, diisopropyl ether, 2-butanone, and methanol.

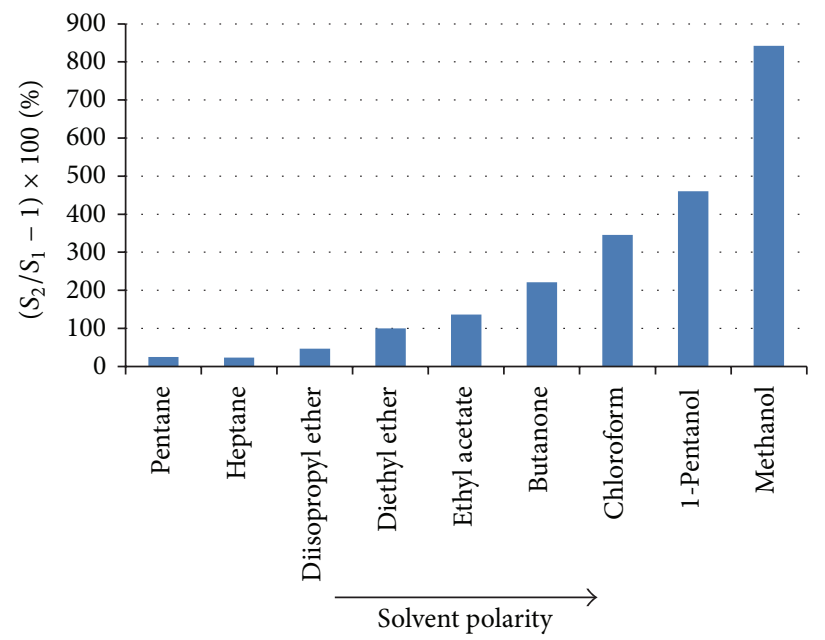

FIGURE 8: The ratio $S_{2} / S_{1}-1$ calculated as the increase in MWCNT $\left(\mathrm{BuNH}_{2}\right)$ sensitivity with respect to sensitivity of pure MWCNT in trend of increased VOC polarity defined by total Hildebrand solubility parameter.

prepare layered composites of entangled networks deposited on polyurethane supporting nonwoven membrane. The response of composite sensors to organic solvent vapors in a broad range of polarities (defined by Hansen solubility parameters) was measured by the change of electrical resistance as a response to physisorption and desorption of vapors. In case of highly polar methanol, the functionalized network response was more than eightfold higher in comparison to the network prepared from pristine nanotubes.

The mechanism of the resistance change may be explained by formation of nonconducting layers between nanotubes owing to exposure to solvent vapors. The functionalization considerably increases the resistance of composite sensor in comparison to the sensor with pristine nanotubes. 
It suggests that there is a relation between the strength of the van der Waals forces and the sensor response of MWCNT $\left(\mathrm{BuNH}_{2}\right)$ network. Stronger interactions between the VOCs and the network can induce the higher sensing response of the network. The sum of $\delta_{h}$ and $\delta_{d}$ of VOCs can have effect on the sensor responses based on dipole-dipole and hydrogen bonding interactions between the network and the VOCs.

\section{Conflict of Interests}

The authors declare that there is no conflict of interests regarding the publication of this paper.

\section{Acknowledgments}

This project was supported by the internal Grant of TBU in Zlin no. IGA/FT/2014/013 funded from the resources of the Specific University Research, by the operational program Research and Development for Innovations cofunded by the European Regional Development Fund (ERDF), by the National Budget of the Czech Republic within the framework of the Centre of Polymer Systems project (reg. no.: CZ.1.05/2.1.00/03.0111), and by the Ministry of Education, Youth and Sports of the Czech Republic within the framework of the Czech-Argentina bilateral cooperation 7AMB13AR019. U. Cvelbar would gratefully like to acknowledge financial support from Slovenian Research Agency (ARRS).

\section{References}

[1] P. Slobodian, P. Riha, A. Lengalova, P. Svoboda, and P. Saha, "Multi-wall carbon nanotube networks as potential resistive gas sensors for organic vapor detection," Carbon, vol. 49, no. 7, pp. 2499-2507, 2011.

[2] R. Benlikaya, P. Slobodian, and M. Machovsky, "Comparison of vapor sensing properties of pristine and hexamethylene diamine-treated MWCNT networks to primary, secondary and tertiary alcohols," Key Engineering Materials, vol. 605, pp. 239242, 2014.

[3] R. Benlikaya, P. Slobodian, P. Riha, and R. Olejnik, "The enhanced alcohol sensing response of multiwalled carbon nanotube networks induced by alkyl diamine treatment," Sensors and Actuators B: Chemical, vol. 201, pp. 122-130, 2014.

[4] Y. Zhao and W. Li, "Effect of annealing and $\mathrm{HNO}_{3}$-treatment on the electrical properties of transparent conducting carbon nanotube films," Microelectronic Engineering, vol. 87, no. 4, pp. 576-579, 2010.

[5] C. K. Liu, M. Huang, J. M. Wu, and H. C. Shih, "Effect of plasma modification of single wall carbon nanotubes on ethanol vapor sensing," Diamond and Related Materials, vol. 19, no. 7-9, pp. 981-987, 2010.

[6] C. Liu, J. Wu, and H. C. Shih, "Application of plasma modified multi-wall carbon nanotubes to ethanol vapor detection," Sensors and Actuators, B: Chemical, vol. 150, no. 2, pp. 641-648, 2010.

[7] H. Xie, C. Sheng, X. Chen, X. Wang, Z. Li, and J. Zhou, "Multi-wall carbon nanotube gas sensors modified with aminogroup to detect low concentration of formaldehyde," Sensors and Actuators B: Chemical, vol. 168, pp. 34-38, 2012.
[8] F. Mohammadzadeh, M. Jahanshahi, and A. M. Rashidi, "Preparation of nanosensors based on organic functionalized MWCNT for $\mathrm{H}_{2} \mathrm{~S}$ detection," Applied Surface Science, vol. 259, pp. 159-165, 2012.

[9] P. Slobodian, P. Riha, A. Lengalova, and P. Saha, "Compressive stress-electrical conductivity characteristics of multiwall carbon nanotube networks," Journal of Materials Science, vol. 46, no. 9, pp. 3186-3190, 2011.

[10] K. A. Wepasnick, B. A. Smith, K. E. Schrote, H. K. Wilson, S. R. Diegelmann, and D. H. Fairbrother, "Surface and structural characterization of multi-walled carbon nanotubes following different oxidative treatments," Carbon, vol. 49, no. 1, pp. 24-36, 2011.

[11] R. Benlikaya, P. Slobodian, and P. Riha, "Enhanced straindependent electrical resistance of polyurethane composites with embedded oxidized multiwalled carbon nanotube networks," Journal of Nanomaterials, vol. 2013, Article ID 327597, 10 pages, 2013.

[12] D. Roy, N. Tiwari, K. Mukhopadhyay, and A. K. Saxena, "The effect of a doubly modified carbon nanotube derivative on the microstructure of epoxy resin," Polymer, vol. 55, pp. 583-593, 2014.

[13] V. Datsyuk, M. Kalyva, K. Papagelis et al., "Chemical oxidation of multiwalled carbon nanotubes," Carbon, vol. 46, no. 6, pp. 833-840, 2008.

[14] W. M. Silva, H. Ribeiro, L. M. Seara et al., "Surface properties of oxidized and aminated multi-walled carbon nanotubes," Journal of the Brazilian Chemical Society, vol. 23, no. 6, pp. 1078-1086, 2012.

[15] T. Ohtake, "ATR-FTIR and XPS evaluationof Alkyl immobilization by hydrosilylation on $\mathrm{n}-\mathrm{Si}(111)$ for photoelectrochemical cell electrode," Journal of Surface Engineered Materials and Advanced Technology, vol. 3, no. 3, pp. 7-10, 2013.

[16] A. Ansón, J. Jagiello, J. B. Parra et al., "Porosity, surface area, surface energy, and hydrogen adsorption in nanostructured carbons," Journal of Physical Chemistry B, vol. 108, no. 40, pp. 15820-15826, 2004. 

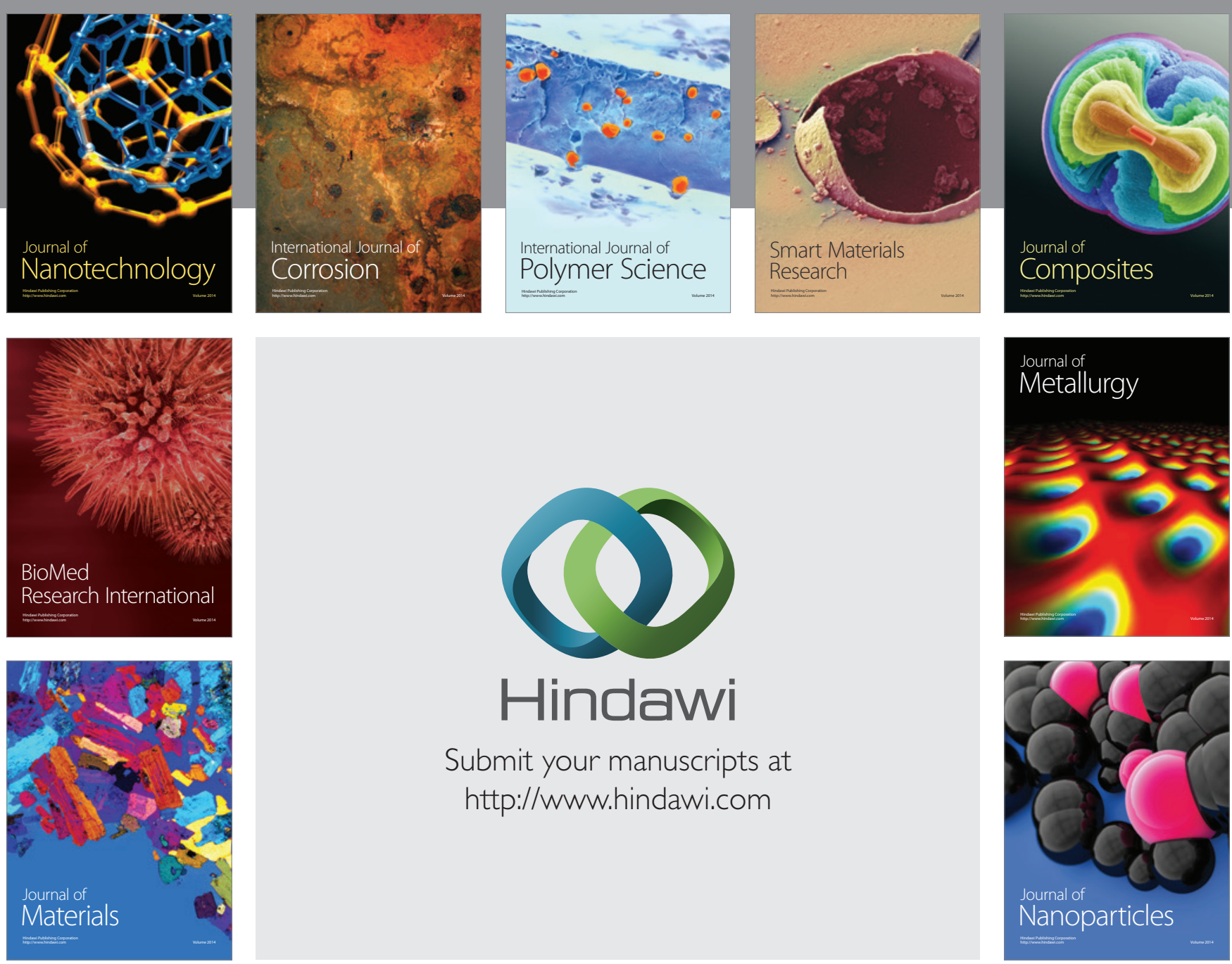

Submit your manuscripts at http://www.hindawi.com
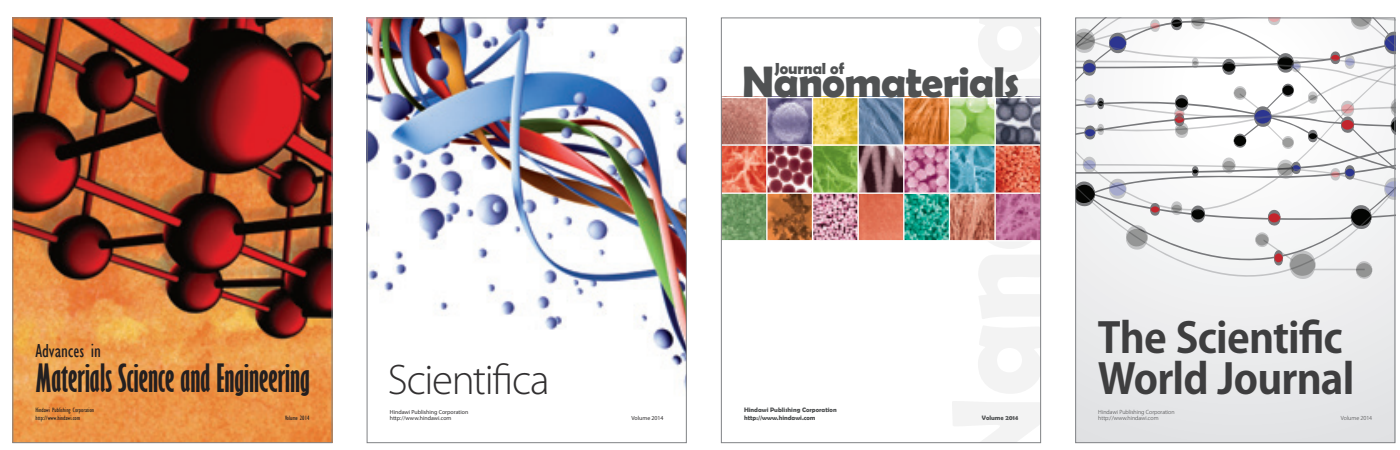

\section{The Scientific World Journal}
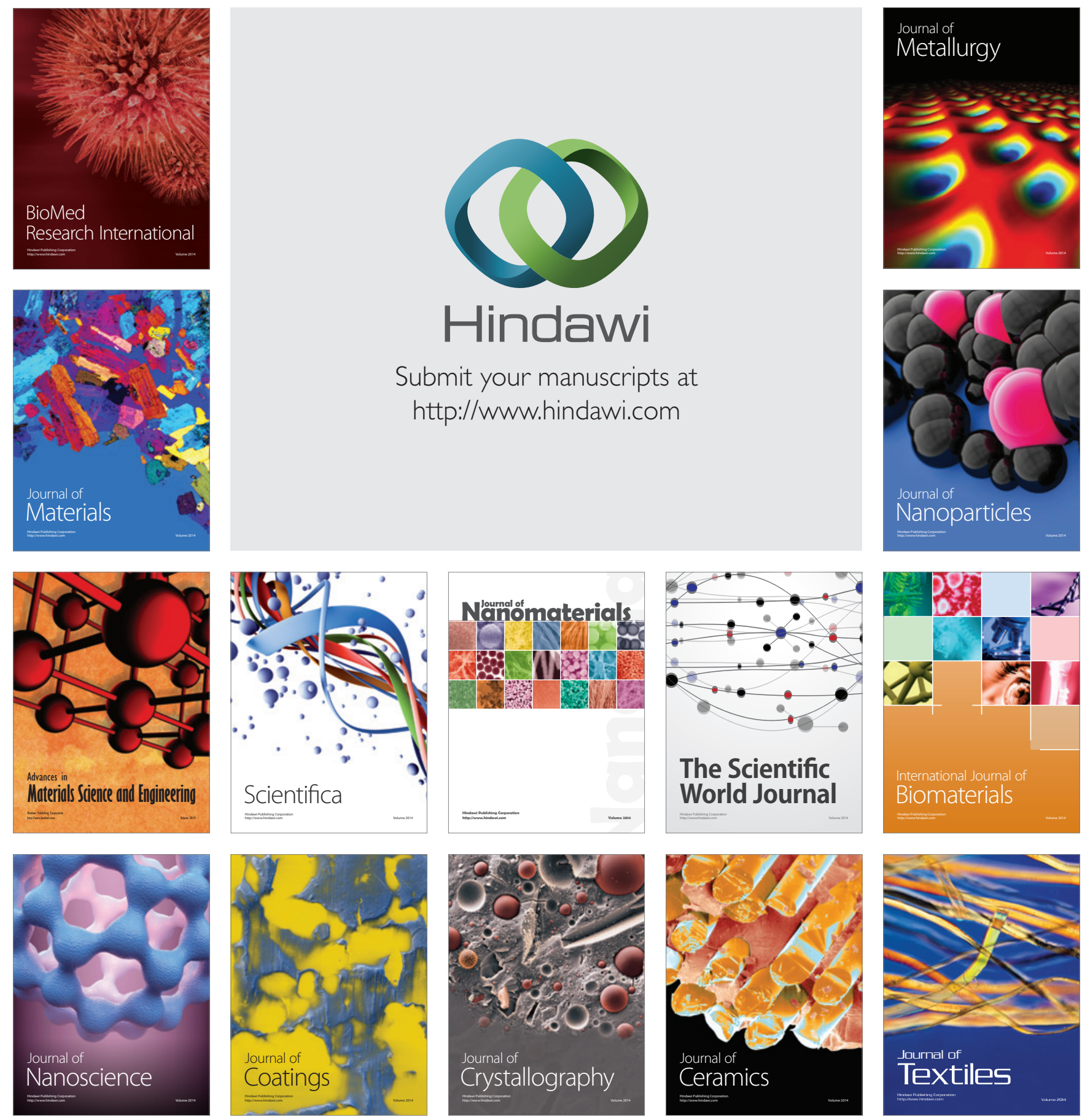